\title{
Cytogenetic effects by newly synthesized antineoplastic steroidal alkylators in cultured human lymphocytes
}

\author{
Mourelatos $\mathrm{C}^{1}$, Kareli $\mathrm{D}^{1}$, D \\ Th $\mathrm{S}^{1}$ and Mourelatos $\mathrm{D}^{2 *}$ \\ ${ }^{1}$ Laboratory of Genetics, Medical School, Dimokrition University of Thrace, 68100, Alexandroupolis, Greece \\ ${ }^{2}$ Lab of Med Biol and Genetics Med Faculty Aristotle University 54124 Thessaloniki, Greece \\ ${ }^{3}$ Laboratory of Pharmaceutical Chemistry, University of Patras, Greece
}

\begin{abstract}
We synthesized eight new antitumor agents combining nitrogen mustard with steroidal skeleton to improve specificity and reduce toxicity. We compared them on a molar basis regarding their ability to induce Sister Chromatid Exchanges (SCEs) and modify Proliferation Rate Indices (PRIs) in cultured human lymphocytes. The compounds tested have as alkylators either p-N, N-bis(2-chloroethyl) aminophenyl-butyrate (CHL) or p-N, N-bis(2-chloroethyl) aminophenyl-acetate (PHE) esterified with different modified steroidal nucleus. A distinct cytogenetic effect was achieved by the compounds which contain either PHE or CHL as alkylators and are esterified with either a steroidal nucleus having inserted exocyclically a -NHCO- group in the D ring or with a steroidal nucleus having inserted a cholesten group in the 17 positions of the D-ring. However, the -NHCO- group or the ketone group in the $\mathrm{D}$ ring being inserted endocyclically in the steroidal nuclei esterified with either PHE or CHL gave negative cytogenetic effects. A correlation was observed between the magnitudes of the SCE response, the depression of PRIs, in normal human lymphocytes in vitro and previously established cytogenetic and antineoplastic effects by the same compounds in cancer rodent cells in vivo.
\end{abstract}

\section{Introduction}

This research was undertaken in order to assess the genotoxic and cytostatic effects of 8 newly synthesized antineoplastic steroidal alkylators upon culture human lymphocytes. For genotoxicity evaluation the SCE assay was employed and as an indicator of cytostatic activity the PRIs were used. It has been reported $[1,2]$ that in different cell lines differential SCEs inductions have been identified by a given antineoplastic treatment, a fact which has been attributed to the different cell types used: In the cell line in which negative results in SCE induction were identified, negative antineoplastic effects were also obtained, while in the cell line where positive effects in SCE induction (by the same treatment) were established, positive antineoplastic results were also identified. The pathways leading to SCEs seem that are different in different cell lines [1,2]. Therefore, since human lymphocytes constitute the dosimeter [1] of exposure to genotoxic antitumor agents, it is reasonable to investigate the extent of their sensitization by the same, already in cancer rodent cells in vivo tested for cytogenetic and antineoplastic activity, compounds.

\section{Materials and methods}

The synthetic procedures and the cytogenetic and antineoplastic in vivo effects of these 1-8 compounds have been previously upon rodent cancer cells established [3]. The 1-8 tested compounds are (Figure 1):

Comp. 1:3 $\beta$-hydroxy-androst-5,7-dien-17-one-4-N,N-bis(2-chloroethyl) aminophenylbutyrate.

Comp. 2:33-hydroxy-androst -5,7-dien-17-one-4-N,N-bis(2-chloroethyl) aminophenylacetate.

Comp.3:3 $\beta$-hydroxy-chlest-5,7-dien-4-N,N-bis(2-chloroethyl) aminophenylbutyrate.
Comp.4:3 $\beta$-hydroxy-chlest-5,7-dien-4-N,N-bis(2-chloroethyl) aminophenylacetate.

Comp.5:3 $\beta$-hydroxy-17 $\beta$-acetamido-androst-5,7-dien-4N,N-bis(2chloroethyl)amiphenylbutyrate.

Comp.6:3 $\beta$-hydroxy-17 $\beta$-acetamido-androst-5,7-dien-4N,N-bis(2chloroethyl)aminophenylacetate.

Comp.7:3 $\beta$-hydroxy-17 $\alpha$-aza-D-homo-androst-5,7-dien-17-one$4 \mathrm{~N}, \mathrm{~N}$-bis(2-chloroethyl)aminophenylbutyrate.

Comp.8:3 $\beta$-hydroxy-17 $\alpha$-aza-D-homo-androst-5,7-dien17-one$4 \mathrm{~N}, \mathrm{~N}$-bis(2-chloroethyl)aminophenylacetate.

Human lymphocyte cultures were set up by adding 11 drops of heparinized whole blood from normal subjects to $5 \mathrm{ml}$ chromosome medium 1A (RPMI 1640, Biochrom Berlin). For SCE demonstration 5 $\mu \mathrm{g} / \mathrm{ml}$ of Bromodeoxyuridine (BrDurd) and the compounds were added at the beginning of culture life. During the period of the experiments all cultures were maintained in the dark to avoid photolysis of BrDurd. The cultures were incubated for $72 \mathrm{~h}$ at $37^{\circ} \mathrm{C}$. Colchicine $(0.3 \mu \mathrm{g} / \mathrm{ml})$ was added $2 \mathrm{~h}$ before harvesting. The cells after centrifugation were treated with $0,075 \mathrm{M} \mathrm{KCL}$ for $10 \mathrm{~min}$. They were fixed with methanol:glacial acetic acid (3:1) and air dried. The differential staining of SCEs was made using the Fluorescence Plus Giemsa (FPG) technique (4). For mean SCE calculation at least $302^{\text {nd }}$ division metaphases were evaluated.

Correspondence to: Mourelatos D, Lab of Med Biol and Genetics Med Faculty Aristotle University 54124 Thessaloniki, Greece, Tel: +30 2310 999017; E-Mail: dmourela@auth.gr

Received: October 03, 2017; Accepted: October 24, 2017; Published: October 26,2017 


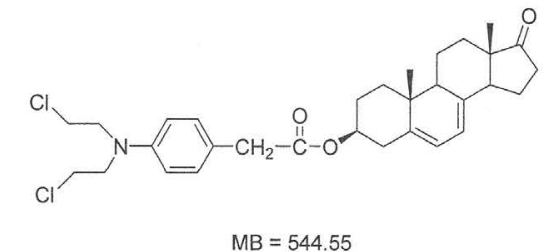

CODE: 002<smiles>CC(C)CCCC1CCC2C3=CC=C4CC(OC(=O)Cc5ccc(N(CCCl)CCCl)cc5)CCC4(C)C3CCC12C</smiles><smiles>CC(=O)NC1CCC2C3=CC=C4CC(OC(=O)Cc5ccc(N(CCCl)CCCl)cc5)CCC4(C)C3CCC12C</smiles>

$M B=587.62$<smiles>C[C@@]12CCC3C(=CC=C1C[C@@H](OC(=O)Cc1ccc(N(CCCl)CCCl)cc1)CC2)C1CCC(=O)N[C@@]13C</smiles>

$\mathrm{MB}=559.57$
CODE: 004

CODE: 006

CODE: 008

Figure 1. Newly synthesized compounds.

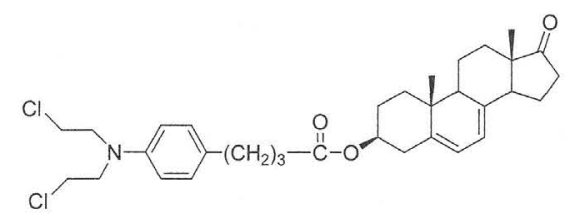

CODE: 001

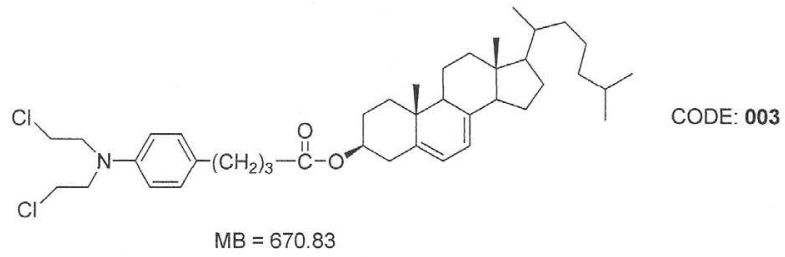<smiles>CC(=O)NC1CCC2C3=CC=C4C[C@@H](OC(=O)CCc5ccc(N(CCCl)CCCl)cc5)CC[C@]4(C)C3CCC12C</smiles>

CODE: 005

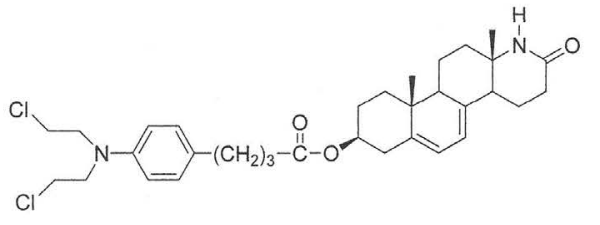

$M B=587.62$

CODE: 007

001: androstene ester of CHL

003: cholestene ester of CHL

005: amide ester of $\mathrm{CHL}$

007: lactan ester of $\mathrm{CHL}$

002: androstene ester of PHE

004: cholestene ester of PHE

For PRIs the total number of cells evaluated from each culture was of 100-200 cells. The PRI $=(\mathrm{M} 1+2 \mathrm{M} 2+3 \mathrm{M} 3+) / \mathrm{N}$, where M1, M2, M3 ${ }^{+}$ indicate the number of metaphases in the $1^{\text {st }}, 2^{\text {nd }}$ and $3^{\text {rd }}$ or subsequent divisions, $\mathrm{N}$ is the total number of metaphases scored. Unpaired t test and $\mathrm{x}^{2}$ tests were used for statistical evaluation of SCE values and PRIs respectively. For the assessment of correlations between the SCEs and PRI frequencies, Pearson test ( $r$ correlation coefficient) was applied.

\section{Results and discussion}

Compounds $1,2,7,8$ gave marginally negative cytogenetic results in human lymphocytes in vitro (Table 1) and in leukemia P388 cells in vivo [3]. The same compounds gave negative antineoplastic effects in BDF1 mice inoculated with lymphocytic leukemia P388 cells [3]. Compounds 3 and 4, which include either CHL (comp.3) or PHE (comp.4) as alkylators and they are esterified with a steroidal nucleus with cholesten at the $17^{\text {th }}$ position, gave distinct in vitro (Table 1 ) and in vivo [3] results: Comp. 4 compared with comp. 3 was more effective at lower concentrations $(0.2$ and $0.4 \mu \mathrm{M})$, while at higher concentrations $(0.6$ and $1.2 \mu \mathrm{M})$ in vitro (Table 1$)$ and in vivo [3] the opposite holds true, with comp. 3 being more effective compared to comp. 4 in SCE induction, PRI suppression (Table 1[3]) and antileukemic activity
[3]. Compounds 5 and 6, which include either CHL (comp.5) or PHE (comp.6) as alkylators and they are esterified with a steroidal nucleus having added exocyclically the - NHCO-group in the D ring, gave positive cytogenetic results in human lymphocytes in vitro (Table 1), as well as positive cytogenetic and antineoplastic effects in leukemia P388 cells in vivo [3]. Comp. 6 was proved, compared with comp.5 on a molar basis, more effective at the concentrations tested (Table 1) in inducing SCEs and in depressing PRIs in human lymphocytes in vitro (Table 1). In leukemia P388 cells in vivo comp. 6 was also proved more effective compared with comp. 5 in inducing SCEs and antineoplastic effects on survival of BDF1 mice inoculated with leukemia P388 cells [3]. A correlation was observed between the magnitudes of the SCE response, the depression of PRIs, in normal human lymphocytes in vitro (Table $1, \mathrm{p}<0,02$ at the concentration of $0,6 \mu \mathrm{M}$ and $\mathrm{p}<0,01$ at the concentration of $1,2 \mu \mathrm{M})$ and previously established cytogenetic and antineoplastic effects by the same compounds in cancer rodent cells in vivo.

The present findings suggest that cytogenetic in vitro upon normal human cells and in vivo upon cancer rodent cells effects of the eight compounds tested in conjunction with the antineoplastic activity of these agents depend on the configuration of the molecule and the appropriate combination of the alkylator with the steroidal molecule. 
Table 1. Cytogenetic effects of compounds 1-8 in human lymphocytes in vitro. S.E.M. = Standard Error of the Mean.

\begin{tabular}{|c|c|c|c|}
\hline & Compounds Concentr. $(\boldsymbol{\mu M})$ & SCEs/cell \pm S.E.M. \\
\hline Control & & $7,25 \pm 0,89$ \\
\hline 1 & 0,2 & $10,51 \pm 0,73^{\mathrm{a}}$ \\
\hline 2 & 0,2 & $7,66 \pm 0,78$ \\
\hline 3 & 0,2 & $1,28^{\mathrm{b}}$ \\
\hline 4 & 0,2 & $1,54^{\mathrm{b}}$ \\
\hline 5 & 0,2 & $1,37^{\mathrm{b}}$ \\
\hline 6 & 0,2 & $1,25,37 \pm 1,84^{\mathrm{a}}$ \\
\hline 7 & 0,2 & $39,75 \pm 0,66^{\mathrm{a}}$ \\
\hline 8 & 0,2 & $8,90 \pm 3,28^{\mathrm{a}}$ \\
\hline
\end{tabular}

a Statistically significant increase compared with control ( $p<0,01$ unpaired t-test).

bStatistically significant decrease compared with control $\left(\mathrm{p}<0,01 \mathrm{x}^{2}\right.$-test $)$.

\begin{tabular}{|c|c|c|c|}
\hline & Compounds Concentr. $(\boldsymbol{\mu M})$ & SCEs/cell \pm S.E.M. \\
\hline Control & & $9,62 \pm 0,89$ \\
\hline 1 & 0,4 & $8,98 \pm 1,18$ \\
\hline 2 & 0,4 & $21,08 \pm 1,94^{\mathrm{a}}$ \\
\hline 3 & 0,4 & $22,65 \pm 2,37^{\mathrm{a}}$ \\
\hline 4 & 0,4 & $14,65 \pm 1,63^{\mathrm{a}}$ \\
\hline 5 & 0,4 & $4,47^{\mathrm{b}}$ \\
\hline 6 & 0,4 & 1,54 \\
\hline 7 & 0,4 & $10,83 \pm 3,68^{\mathrm{a}}$ \\
\hline 8 & 0,4 & $9,55 \pm 1,02$ \\
\hline
\end{tabular}

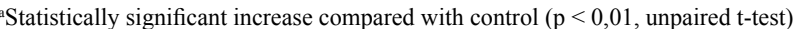

bStatistically significant decrease compared with control $\left(\mathrm{p}<0,01, \mathrm{x}^{2}\right.$-test $)$

\begin{tabular}{|c|c|c|c|}
\hline & Compounds Concentr. $(\mu \mathrm{M})$ & SCEs/cell \pm S.E.M. & PRI \\
\hline Control & & $7,75 \pm 0,94$ & 2,77 \\
\hline 1 & 0,6 & $14,79 \pm 1,03$ & 1,28 \\
\hline 2 & 0,6 & $13,93 \pm 1,23$ & 1,54 \\
\hline 3 & 0,6 & $40,52 \pm 3,62$ & 1,37 \\
\hline 4 & 0,6 & $27,61 \pm 2,61$ & 1,9 \\
\hline 5 & 0,6 & $15,81 \pm 1,43$ & 1,76 \\
\hline 6 & 0,6 & $30,00 \pm 2,11$ & 1,85 \\
\hline 7 & 0,6 & $15,33 \pm 1,12$ & 2,11 \\
\hline 8 & 0,6 & $9,80 \pm 0,95$ & 2,09 \\
\hline \multicolumn{4}{|c|}{ SCEs were correlated with corresponding values of PRIs $(r=-0,43, t=2,61$ and $p<0,02)$} \\
\hline & Compounds Concentr. $(\mu \mathrm{M})$ & SCEs/cell \pm S.E.M. & PRI \\
\hline Control & & $10,05 \pm 0,95$ & 2,36 \\
\hline 1 & 1,2 & $11,65 \pm 0,75$ & 1,92 \\
\hline 2 & 1,2 & $18,70 \pm 1,04$ & 1,98 \\
\hline 3 & 1,2 & $117,42 \pm 7,24$ & 1,34 \\
\hline 4 & 1,2 & $81,66 \pm 6,37$ & 1,45 \\
\hline 5 & 1,2 & $38,10 \pm 3,23$ & 2,16 \\
\hline 6 & 1,2 & $86,28 \pm 5,20$ & 1,66 \\
\hline 7 & 1,2 & $18,28 \pm 1,19$ & 2,19 \\
\hline 8 & 1,2 & $86,28 \pm 5,20$ & 2,08 \\
\hline
\end{tabular}

In a previous study the in vivo in cancer cells SCE induction by potential antineoplastics was positively correlated with in vivo tumor chemoresponse to these eight agents [3]. In the present study the same potential antineoplastics were tested in vitro upon cultured normal human lymphocytes in search for a possible relationship between genotoxic and cytostatic activity in vitro in normal cells and antineoplastic activity in vivo in cancer cells. It is apparent from the results in Table 1 and in the study with reference to study of Mourelatos $\mathrm{C}$ [3] that the order of the cytogenetic in vitro and in vivo effects of the eight compounds tested resembles with the order of antitumor effectiveness they induce. SCEs have been frequently employed in cancer research as highly sensitive indicators of DNA damage and/or subsequent repair $[1,5]$. DNA repair and genotoxic exposure to cancer chemotherapeutics are expected to vary among patients, therefore correlating SCE frequencies with only individual repair capacity may be feasible to predict [1].
Furthermore, there are findings suggesting that the effectiveness in SCE induction by potential antineoplastics in normal cells in vitro and in cancer cells in vivo is positively correlated with in vivo tumor response to these agents $[1,5]$. It is worth mentioning that since the SCE assay is based on the analysis of individual cells it can be used to predict both the heterogeneity of drug sensitivity of individual tumors and the sensitivity of human tumor cells to chemotherapeutics $[1,4]$. Unrepaired DNA damage expressed as SCEs in normal cells induced by certain chemicals, may indicate an inability to repair damage induced by the same chemicals in malignant cells, since both cell types have similar DNA repair mechanisms [1,4]. Other studies investigating a relationship between SCE induction and other expressions of genotoxicity have shown a positive relationship between SCE induction, alterations in cell cycle kinetics and reduced cell survival. In the present study, a strong correlation between SCE induction, PRI depression 
(Table 1) and previously established [3] antitumor activity was observed. It therefore appears that the hypothesis about a correlation of the effectiveness in SCE induction by potential antitumor agents in normal human cells in vitro and in cancer rodent cells in vivo with an in vivo tumor response to these agents is further substantiated. As a consequence the SCE assay appears to have an application in prognosis of cancer chemotherapy, in assessing interindividual variation in the response to cancer chemotherapy and in quantitating heterogeneity of drug sensitivity among cell subpopulation of a tumor $[1,4,5]$.

\section{References}

1. Mourelatos D (2016) Sister chromatid exchange assay as a predictor of tumor chemoresponse. Mutat Res Genet Toxicol Environ Mutagen 803-804: 1-12. [Crossref]
2. Eliopoulos P, Mourelatos D, Dozi-Vassiliades J (1995) Comparative study on Salmonella mutagenicity and on cytogenetic and antineoplastic effects induced by cyclophosphamide and 3-aminobenzamide in cells of three transplantable tumours in vivo. Mutat Res 342: 141-146.

3. Mourelatos C, Kareli D, Dafa E (2012) Cytogenetic and antineoplastic effects by newly synthesised steroidal alkylators in lymphocytic leukaemia P388 cells in vivo. Mutat Res 746: 1-6.

4. Mylonaki E, Manika K, Zarogoulidis P, Domvri K, Voutsas V, et al. (2012) In vivo synergistic cytogenetic effects of aminophylline on lymphocyte cultures from patients with lung cancer undergoing chemotherapy. Mutat Res 740: 1-5.

5. Mourelatos D, Dozi-Vassiliades J, Kotsis A, Gourtsas C (1988) Enhancement of cytogenetic damage and of antineoplastic effect by caffeine in Ehrlich ascites tumor cells treated with cyclophosphamide in vivo. Cancer Res 48: 1129-1131. [Crossref]

Copyright: $\odot 2017$ Mourelatos C. This is an open-access article distributed under the terms of the Creative Commons Attribution License, which permits unrestricted use, distribution, and reproduction in any medium, provided the original author and source are credited. 